\title{
Study on Sino-US Intra-industry Trade from the Perspective of Intra-product International Specialization
}

\author{
Xiaoming Qiao \\ Journal Editorial Department, Yunnan Normal University, Kunming, 650092, China
}

Keywords: Sino-US, Intra-product international specialization, Intra-industry trade

\begin{abstract}
From the perspective of the China's participation of intra-product international specialization, this paper analyzes the development of parts and components trade and processing trade of China, and accounts the level of intra-industry trade of Sino-US main trade commodities between 1987 and 2006. It shows that the Sino-US trade structure and the level of Sino-US intra-industry trade had been apparently improved during this period. Then the paper analyzes the influential factors of the level of Sino-US intra-industry trade based on the intra-product international specialization by empirical study. It shows that the intra-product international specialization has obvious effect on promoting the level of intra-industry trade of Sino-US high technology industries, medium technology industries and total industries. Therefore, the further improvement of China's position in the intra-product international specialization is of great significance to improve the level of Sino-US intra-industry trade.
\end{abstract}

\section{Introduction}

Intra industry trade has always been an important field in the study of international trade. Since the pioneering research on Verdoorn (1960) [1], Balassa (1966) [2], Grubel and Lloyd (1975) [3] and other scholars, intra industry trade has made great progress both in theoretical research and empirical analysis. From the previous research of intra industry trade, there are two major limitations: one is theoretical analysis, assuming that products are basically the final product, and ignored the 1990s international intra product specialization of intermediate product trade based on the consideration, since, with the deepening of economic globalization, countries within the division of labor within the industry and the product of the division of labor is increasingly close, intermediate product trade continues to expand, cross-border production process involved in the international division of labor segmentation inner products, which will lead to some parts and intermediate products in a production process with outsourcing to some other parts and intermediate products to other countries in exchange. Because these parts, intermediate products and processed products are often classified into the same industry, so the international division of labor within the product is triggered. The import and export of such products can form intra industry trade, that is, intra product specialization is another important cause of intra industry trade. The two is empirical research. It mainly studies intra industry trade among developed countries, but ignores the research on intra industry trade between developing countries and developed countries and developing countries. This paper tries to explore the influencing factors of intra industry trade between developing and developed countries (Sino US trade as an example) from the new perspective of China's participation in intra product specialization [4].

\section{Participation of China in Intra-product International Specialization and Current Situation of Sino-US Intra-industry Trade}

\subsection{Current Situation of Participation of China in Intra-product International Specialization}

An important factor in China's import and export growth since 1990s is the expansion of the 
processing trade based on the international division of labor within the product. China's processing trade is mostly in the middle of 1980s. Since the middle of 1980s, the newly industrialized economies such as the United States, Japan and other new industrialized economies such as Asia have developed to reduce production costs and enhance competitiveness, and transfer labor-intensive industries or processes to China.

With the further development of the knowledge economy, gradually formed $\mathrm{V}$ production structure, namely the United States and Europe, Japan and South Korea engaged in R \& D, design and other capital intensive production activities, production and export of key parts of ASEAN and Taiwan; the production and export of components or modules; China, engaged in labor-intensive assembly and provide a small amount of components; in Hongkong for the United States and other overseas markets and marketing services, while the United States has become the target market products and realize the value of the products. The import proportion of Chinese parts and components accounts for the increase of the proportion of China's imports year by year. In the past 20 years, China's participation in international division of labor has deepened greatly.

\subsection{Current Situation of Sino-US Intra-industry Trade}

Manufactured goods have always been the main commodities of Sino US trade, accounting for more than $90 \%$ of the trade between China and the United States. Considering the representativeness of the research and the size of the sample space, we choose 15 chapters to study the development level of Sino US intra industry trade. The 15 chapters, the proportion of manufactured imports and exports to Sino US trade has increased from 52\% in 1992 to 71\% in 2006. Meanwhile, referring to OECD's classification method of manufacturing industry according to R \& D intensity, we can divide these 15 chapters into three categories: high tech industry, medium technology industry and low technology industry.

In short, although the past 20 years the level of trade in American products industry increased significantly, but the level of trade in manufactured products in the industry is still low, the huge trade deficit and low level of intra industry trade in Sino US trade is not conducive to the benign interaction and China's economic structure optimization. On the one hand, in recent years, trade frictions between China and the US have been continuous. The US has taken anti-dumping measures, implemented various trade barriers to Chinese goods, and put pressure on RMB appreciation to bring many adverse effects to Sino US trade. On the other hand, some export enterprises in China are expanding blindly, resulting in the problems of excessive growth of investment and the economic structure of overcapacity in some industries. Therefore, targeted analysis of the factors affecting Sino US intra industry trade is of great practical significance for improving bilateral trade level, achieving Sino US trade sustainable development and optimizing China's industrial structure.

\section{Empirical Analysis of Influence on Sino-US Intra-industry Trade of Intra-product International Specialization}

\subsection{Model Setting and Data Resource}

To verify the effect of China participation in international intra product specialization on Sino US intra industry trade, need to establish econometric models to test, according to the research on the influence factors of the intra industry trade, including per capita income level, the degree of dependence on foreign trade, trade imbalances, foreign direct investment, exchange rate is also an important factor affecting intra industry trade the. Therefore this paper selects the econometric model as explanatory variables: on behalf of China participate in processing trade products within the international division of labor degree accounted for the proportion of total foreign trade Chinese (represented by JGBZ); in 1987 China's per capita GDP index base period (RGDP), the degree of dependence on foreign trade Chinese (represented by OPEN), American direct investment in China accounted for the proportion of foreign investment in China (FDI), the U.S. dollar against the RMB exchange rate (EX), the trade imbalance degree (IMBAL). The explanatory variables are the Sino US 
intra industry trade index, and the high-tech intra industry trade index is expressed in HGL. The middle technology intra industry trade index is expressed by MGL. The low tech intra industry trade index is expressed in LGL, and the total intra industry trade index is expressed in TGL. In order to investigate the influence of explanatory variables on Sino US intra industry trade level, a logarithmic model (1) is established, which can be represented by respectively

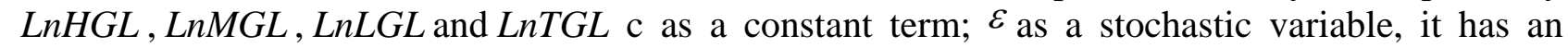
impact on intra industry trade.

$$
L n * G L=c+\beta_{1} L n J G B Z+\beta_{2} L n F D I+\beta_{3} L n I M B A L+\beta_{4} L n R G D P+\beta_{5} L n O P E N+\beta_{6} \operatorname{LnEX}+\varepsilon
$$

In the past 1987-2006 years, all trade data came from the second edition of the SITC database of the United Nations Statistics Department (UN COMTRADE). In 1987-2006, China's per capita GDP, FDI and US dollar exchange rate came from the Yearbook of China Statistics. The intra industry trade index (intra - industry trade index) is based on the formula 1 and 2, which calculates the intra Industrial Trade Index of the major manufactured goods in China and the United States for 1987-2006 years in the income Table 1.

Table 1. Intra-industry trade of main manufacture products in China and America from 1987 to 2006.

\begin{tabular}{c|c|c|c|c}
\hline Year & High tech industry & Medium tech industry & Low tech industry & Over manufacture products \\
\hline 1987 & 0.077 & 0.168 & 0.076 & 0.109 \\
1988 & 0.099 & 0.223 & 0.093 & 0.145 \\
1989 & 0.174 & 0.204 & 0.080 & 0.152 \\
1990 & 0.187 & 0.296 & 0.073 & 0.170 \\
1991 & 0.239 & 0.304 & 0.052 & 0.177 \\
1992 & 0.349 & 0.286 & 0.033 & 0.176 \\
1993 & 0.474 & 0.288 & 0.032 & 0.225 \\
1994 & 0.528 & 0.307 & 0.032 & 0.266 \\
1995 & 0.536 & 0.343 & 0.039 & 0.298 \\
1996 & 0.500 & 0.378 & 0.041 & 0.302 \\
1997 & 0.418 & 0.408 & 0.041 & 0.277 \\
1998 & 0.445 & 0.386 & 0.036 & 0.298 \\
1999 & 0.510 & 0.443 & 0.038 & 0.353 \\
2000 & 0.506 & 0.405 & 0.034 & 0.348 \\
2001 & 0.532 & 0.425 & 0.032 & 0.374 \\
2002 & 0.363 & 0.418 & 0.032 & 0.293 \\
2003 & 0.266 & 0.414 & 0.031 & 0.247 \\
2004 & 0.221 & 0.393 & 0.033 & 0.224 \\
2005 & 0.208 & 0.402 & 0.031 & 0.235 \\
2006 & 0.195 & 0.368 & 0.030 & 0.198 \\
\hline
\end{tabular}

\subsection{Empirical Analysis}

Because time series data often have nonstationary, it is possible to regress directly to two non-stationary time series, which may cause false regression. Therefore, it is necessary to test the stationarity of data. The standard method for checking the stability of the sequence is the unit root test. In this paper, the ADF test of unit root is used to determine the smoothness and the single order of the sample sequence. The original time series data are not stable at $10 \%$ significant level, while the sequence of first order difference is stationary at the level of $10 \%$. Therefore, the original time series are all the first order and stable, and satisfy the precondition of linear regression.

There are differences in the influencing factors of intra industry trade in different types of industries. By using Eviews5.1 software (Yi Danhui, 2002) [5], by substituting the model (1) into the model (1) and eliminating the non-significant variables, we get the four regression results of the factors affecting the intra industry trade of the high, middle and low technology industries and the total manufactured goods. 
According to the regression results, as the main form of intra product specialization in China's processing trade proportion increased $1 \%$, the high technology industry intra industry trade index increased $1.296 \%$ in Chinese products within the international division of labor further promoted the level of Sino US trade of high technology industry in improving. The level of intra industry trade in high tech industry is negatively correlated with the US direct investment in China, indicating that the US investment in China is mainly market-oriented, and it has a tendency to replace its parent company's trade with China in Hua Zi's sales to host countries. The higher the trade imbalance and the degree of dependence on foreign trade of high technology industry intra industry trade level has adverse effect; the level of Sino US trade of high technology industry and the U.S. dollar against the RMB exchange rate is positively related to high technology products in China are not the traditional comparative advantage products, with China's participation in international division of labor intensive sectors deeply. Gradually increase the intermediate and final products of high technology industry's exports, while the United States as China's largest exporter, the strong dollar has important impact on China's high technology products to enter the American market.

The fitting degree of the model to the sample values is high and tested by Durbin-Watson. The T values of all parameters are tested and the model has passed the significance test of equation. According to the regression results, the proportion of processing trade increased by $1 \%$. The intra industry trade index of the secondary technology industry increased by $1.114 \%$. Intra product international division greatly promoted the development of intra industry trade in the secondary technology industry.

Therefore, the fitting degree of the model to the sample values is good, and is verified by Durbin-Watson test. The $T$ value of each parameter is verified by test, and the regression model has passed the significance test of equation. From the regression results, increase the proportion of processing trade $1 \%$, low technology industry intra industry trade index decreased by $0.687 \%$, which is mainly due to China's processing trade is mainly involved in the medium and high technology industry processing and assembling labor-intensive sectors, the low technology industry labor market constitutes a certain competition therefore, the processing trade of low technology industry intra industry trade have negative effects.

According to $\mathrm{R}^{2}=0.877$, the fitting degree of the model is high, and Durbin-Watson test is adopted. The $\mathrm{T}$ values of all parameters are tested. Meanwhile, the model has passed the significance test of equation. From the above knowledge, every increase in processing trade accounted for $1 \%$, the overall intra industry trade index increased by $0.865 \%$, has a great positive role in promoting international intra product specialization on the overall Sino US intra industry trade, this is because, as mentioned earlier, with the adjustment of industrial structure in China, the share of high technology industry and foreign trade gradually increased has been the dominant export industry, trade and processing trade of high technology industry in promoting effect.

\section{Countermeasures and Suggestions of Sino-US Intra-industry Trade Development Based on Intra-product International Specialization}

In the international division of labor is increasingly deepening, China's economy to more effectively participate in international division of labor and trade, not only according to the factor endowment, vigorously develop industries with comparative advantage, more important is to break the shackles of traditional theory, to avoid falling into the trap of comparative advantage ", the development of Sino US intra industry trade, in order to obtain comparative advantage and dynamic competitive advantage. Through the empirical analysis of the factors that affect intra - industry trade between China and the United States, the following several aspects can be made to improve the intra - industry trade level of China and the United States.

(1) Encourage the development of high technology content, high degree of product differentiation of the electronic machinery, communications equipment and other related production, improve the quality of intermediate products and technical content, promote the development of related production processes in the development of key components, to optimize the development of Chinese 
intra industry trade and the trade commodity structure, accelerate trade mode related to the manufactured goods vertical differentiation intra industry trade oriented to differentiated products to the level of intra industry trade transformation.

(2) Promote investment interaction between China and the United States in the field of middle and high technology industries. We should actively guide the investment direction of US businesses, encourage investment in China, set up R \& D centers in China, promote the transfer of the US high-tech industry to China, and support the procurement process of raw materials and intermediate products in China. At the same time, Chinese enterprises should actively go out and invest more in us to reduce China's huge trade surplus to the US and promote the balanced development of bilateral trade.

(3) Increase the import of high - tech products from the United States, which are urgent to our country. The Sino US trade balance distorts the true level of intra industry trade between China and the US. One of the reasons is that the US has many restrictions on the export of high-tech products to China because of political considerations. Therefore, making full use of the WTO rules to strengthen bilateral trade consultation mechanism and expand the import scale of China's urgent high-tech products is of great significance for enhancing the intra industry trade level of China and the US.

\section{References}

[1] Verdoorn, P. J. The Intra-block trade of Benelux[J]. Economic Consequences of the Size of Nations, 1960(7):23.

[2] Balassa. Tariff reductions and trade in manufactures among industrial countries[J]. New york: American Economic Review, 1966(6):78.

[3] Yang Gao, Huang Xianhai. Internal Drivers and the Specialization Status of Under-developed Countries: Evidence from China's High-tech Industry [J]. Social Sciences in China, 2014, 35(2): 106-121.

[4] He Canfei, Chen Hanghang. Participation in global production networks and export product upgrading [J]. Acta Geographica Sinica, 2017, 72(8): 1331-1346. 